\title{
Apolipoprotein J to Creatinine Ratio Measurement
}

National Cancer Institute

\section{Source}

National Cancer Institute. Apolipoprotein / to Creatinine Ratio Measurement. NCI

Thesaurus. Code C111130.

The determination of the ratio of the apolipoprotein J compared to creatinine present in a sample. The measurement may be expressed as a ratio or percentage. 